\title{
OCORRÊNCIA DE ALTERNARIA PADWICKII (GANGULY) EM SEMENTES DE ARROZ (ORYZA SATIVA L.) (POACEAE) PRODUZIDAS EM QUATRO REGIÕES ORIZÍCOLAS DO RIO GRANDE DO SUL E SEU EFEITO SOBRE PLÂNTULAS
}

\author{
C.R.J. de Farias ${ }^{1}$, A.P.S. Afonso ${ }^{2}$, M.F. Brancão ${ }^{1}$, C.R. Pierobom ${ }^{1}$ \\ 1Universidade Federal de Pelotas, Faculdade de Agronomia “Eliseu Maciel”, Departamento de Fitossanidade, \\ CP 354, CEP 96010-900, Pelotas, RS, Brasil. E-mail: candidajacobsen@bol.com.br
}

\section{RESUMO}

A elevada incidência de manchas em grãos de arroz tem sido motivo de preocupação dos produtores de arroz irrigado. Esse trabalho teve como objetivo detectar a ocorrência de Alternaria padwickii em lotes de sementes de arroz produzidas em diferentes regiões orizícolas do RS e também verificar o efeito desse patógeno sobre plântulas. O trabalho foi realizado no Laboratório de Patologia de Sementes da FAEM/UFPel. Foram analisados 123 lotes de sementes de arroz provenientes de 27 cultivares oriundas de quatro regiões do Rio Grande do Sul cedidas pela Embrapa Clima Temperado e pelo Instituto Rio Grandense do Arroz. As amostras foram analisadas pelo método do papel de filtro. Para verificar o efeito d fungo sobre as plântulas foram selecionadas 100 sementes infectadas por A. padwickiie 100 sementes sadias (testemunha) a partir do método do papel de filtro, sendo estas transferidas individualmente para copos plásticos de $50 \mathrm{~mL}$ de capacidade, contendo vermiculita de granulometria fina. Após 21 dias de incubação, avaliou-se a porcentagem de plântulas que emergiram e, com auxílio de uma régua, mediu-se o comprimento da parte aérea (PA) e sistema radicular (SR). A partir do teste de sanidade verificou-se que a região de Camaquã foi a que apresentou maior incidência de $A$. Padwickii $(10,61 \%)$. A presença do fungo reduziu em $88,0 \%$ a emergência das plântulas e, em 36,6\% o comprimento da parte aérea, 25,5\% do sistema radicular.

PALAVRAS-CHAVE: Mancha de grão, sanidade de sementes, morte de plântulas.

\section{ABSTRACT}

OCCURRENCE OF ALTERNARIA PADWICKII (GANGULY) IN LOTS OF RICE (ORYZA SATIVA L.) (POACEAE) SEEDS PRODUCED IN DIFFERENT REGIONSOF RIOGRANDE DOSUL ANDTHEEFFECTOFTHISPATHOGENON PLANTLETS. The growing incidence of kernel spots has been worrying irrigated rice producers. This study was aimed to detect the occurrence of Alternaria padwickii in lots of rice seeds produced in different regions of RS and also to verify the effect of this pathogen on plantlets. The work was carried out in the Seed Pathology Laboratory of FAEM/UFPel. Samples of 123 rice seed lots from 27 varieties from the seed laboratories of Embrapa Temperate Climate and IRGA, the Rice Institute of Rio Grande doSulState, representing the four main rice regions of the state, were analyzed by blotter test method. For the transmission test, 100 seeds infected only by A. padwickii and 100 healthy seeds (as a control) were selected from the blotter tests, and transferred individually to $50-\mathrm{mL}$ plastic cups with vermiculite. After 21 days of incubation the emerged plants were counted and the length of the aerial part and root system was measured. The results of the blotter test indicated the Camaquã region as presenting the higher incidence $(10.61 \%)$. The fungus reduced emergence by $88.0 \%$, the length of the aerial part in the surviving plants by $36.6 \%$, and the length of the root system by $25.5 \%$.

KEY WORDS: Kernel spots, blotter test, seedling death.

\footnotetext{
${ }^{2}$ Embrapa Clima Temperado, Pelotas, RS, Brasil.
} 


\section{INTRODUÇÃO}

A cultura do arroz tem importante papel na alimentaçãohumana, poiséa principal fonte decalorias para grande parte da população mundial e, além disso, desempenha papel sócio-econômico, particularmente na Ásia, onde mais de 90\% de todo arroz cultivadoéconsumido por aproximadamente $60 \%$ da população mundial (WEBStER; GunNeLL, 1992).

No Brasil, em 2005, foram cultivados aproximadamente 4 milhões hectares com arroz, sendo que a produção foi mais de 13 milhões de toneladas (IBGE, 2006). O maior produtor no Brasil é a Região Sul (7.405,3 mil toneladas), seguido pela Região CentroOeste (2.673,8 mil toneladas), Norte (1.594,6 mil toneladas), Nordeste (1.237,5 mil toneladas) e Sudeste (379,7 mil toneladas) (CONAB, 2006).

No entanto, a cultura é atacada por uma série de patógenos, tais como fungos, bactérias, nematóides, insetos e vírus associados às sementes, em diversos países produtores (Ou, 1972; Grotн et al., 1991).

No Rio Grande do Sul, a cultura do arroz irrigado é atacada por diversas doenças, dentre as causadas por fungos destacam-se: Pyricularia grisea, Bipolaris oryzae, Cercospora janseana, Rhizoctonia solani, Gerlachia oryzae, Phoma sorghina, Alternaria padwickii, Alternaria spp., Curvularia lunata e Nigrospora oryzae (Ou, 1972; Soave et al., 1997; Malavolta; Bedendo, 1999; Franco et al., 2001).

Alguns desses patógenos provocam as chamadas manchas dos grãos e a elevada incidência dessas manchas tem sido motivo de preocupação dos produtores de arroz irrigado. A doença inicialmente era atribuída apenas a B. oryzae, entretanto, outras espécies de fungos tais como A. padwickii, vêm sendo detectadas com freqüência em lotes de sementes de arroz, Farias et al., 2004; Franco et al.,2001; Gulart et al., 2005; Islamet al., 2000). Este fungo já foi observado em associação com sementes de arroz em diversos países, incluindo o Brasil (Amorinet al., 1995; Ou, 1972) e mais especificamente no Rio Grande do Sul (Ribeiro, 1979; Ribeiro; MARiot, 1987; Ribeiro, 1989).

Os sintomas de infecção por A. padwickii nas folhas são manchas ovaladas de 3 a 10 mm de diâmetro, inicialmente amareladas, tornando-se cinza claro, com bordos escuros. Nas glumas o sintoma é semelhante, no entanto, as bordas são maiores. Lesões marrom escuras podem surgir nos coleóptilos ou plântulas e, dependendo da severidade, podem causar a morte dessas plântulas (GRотн, 1992).

Esse trabalho teve como objetivo detectar a ocorrência de A. padwickii em lotes de sementes de arroz produzidas em diferentes regiões orizícolas do Rio Grande do Sul e também verificar o efeito desse patógeno sobre plântulas.

\section{MATERIAL E MÉTODOS}

O trabalho foi realizado no Laboratório de Patologia de Sementes do Departamento de Fitossanidade da Faculdade de Agronomia Eliseu Maciel da Universidade Federal de Pelotas. Foram analisados 123 lotes de sementes de arroz provenientes de 27 cultivares oriundas de quatro regiões do Rio Grande do Sul cedidas pelo Laboratório de Sementes da Embrapa Clima Temperado e pelo Instituto Rio Grandense do Arroz (IRGA Camaquã, IRGA Rosário do Sul e IRGA Uruguaiana) (Tabela 1). As amostras de sementes foram analisadas pelo método do papel de filtro (Brasil, 1992). A incubação foi realizada por 7 dias a $25 \pm 2^{\circ} \mathrm{C}$, sendo as sementes submetidas ao regime de $12 \mathrm{~h}$ em presença de luz e $12 \mathrm{~h}$ no escuro. A identificação foi realizada com auxílio de microscópio estereoscópico e, em caso de dúvida, foram feitas lâminas das estruturas fúngicas e observadas ao microscópio composto comum.

Para verificar o efeito do fungo sobre plântulas, foram selecionadas, durante os testes de sanidade 100 sementes infectadas somente por A. padwickii e 100 sementes sadias (testemunha), sendo estas transferidas individualmente para copos plásticos de $50 \mathrm{~mL}$ de capacidade, contendo vermiculita de granulometria fina. Os copos foram acondicionados em potes plásticos fechados (ambiente saturado de umidade) e estes mantidos a $25 \pm 2^{\circ} \mathrm{C}$. Após 21 dias de incubação, avaliou-se a porcentagem de plântulas que emergiram e foram medidos a parte aérea (PA) e sistema radicular (SR).

Posteriormente, o fungo foi isolado de plântulas necrosadas e multiplicados em placas de Petri de 9 cm de diâmetro contendo como meio de cultura BDA (batata-dextrose-agar) e incubados a $25 \pm 2^{\circ} \mathrm{C}$, para posterior inoculação em plântulas, completando assim os postulados de Koch (AMARAL, 1987). Para isso, foram semeadas 200 sementes de arroz em bandejas plásticas contendo como substrato vermiculita de granulometria fina. As bandejas foram mantidas em sala de incubação e, $48 \mathrm{~h}$ antes da inoculação, foram colocadas em recipientes plásticos transparentes, com tampa para manter um ambiente saturado de umidade. Aos 14 dias após a semeadura procedeuse a inoculação das plântulas, com auxílio de um aspersor manual. A concentração de inóculo utilizada foi de $10^{4}$ esporos/mL, ajustada em câmara de Neubauer. Aos 14 dias após a inoculação procedeuse a avaliação de sintomas e/ ou sinais do patógeno. Partes lesionadas das plântulas foram cortadas e transferidas para câmara úmida (caixa gerbox contendo 2 folhas de papel mata borrão umedecidos com água destilada) e incubados por 7 dias para observação do fungo. 
Tabela 1 - Incidência média (\%) de Alternaria padwickii por região e por cultivar, e número de amostras analisadas nos testes de sanidade. Pelotas/RS, 2006.

\begin{tabular}{|c|c|c|c|c|}
\hline \multirow[b]{2}{*}{ Cultivares } & \multicolumn{4}{|c|}{ Regiões } \\
\hline & Camaquã & Pelotas & Rosário do Sul & Uruguaiana \\
\hline Arrank & & & & $0,13(\mathrm{n}=2)$ \\
\hline \multicolumn{5}{|l|}{ BR IRGA 409} \\
\hline BR IRGA 410 & $19,75(n=5)$ & $4,25(\mathrm{n}=7)$ & $6,58(\mathrm{n}=3)$ & $3,00(\mathrm{n}=1)$ \\
\hline IRGA 404 & & $2,25(\mathrm{n}=1)$ & & \\
\hline IRGA 416 & $16,75(\mathrm{n}=1)$ & & & \\
\hline IRGA 417 & $13,95(\mathrm{n}=10)$ & $5,00(\mathrm{n}=4)$ & $1,87(\mathrm{n}=6)$ & $0,17(\mathrm{n}=3)$ \\
\hline IRGA 418 & $4,58(\mathrm{n}=3)$ & & $2,00(\mathrm{n}=2)$ & \\
\hline IRGA 419 & $21,95(n=6)$ & & & \\
\hline IRGA 420 & $0,25(\mathrm{n}=1)$ & & $1,50(\mathrm{n}=2)$ & $2,50(\mathrm{n}=2)$ \\
\hline IRGA 421 & $0,00(\mathrm{n}=1)$ & & & \\
\hline IRGA 422 CL & & $1,11(\mathrm{n}=7)$ & & \\
\hline BRS - Pelotas & $4,58(\mathrm{n}=6)$ & & & $0,00(\mathrm{n}=1)$ \\
\hline BRS -9 & & & & $0,00(\mathrm{n}=1)$ \\
\hline BRS-6 & & & $0,75(\mathrm{n}=2)$ & \\
\hline BRS-7 & & & $1,25(\mathrm{n}=1)$ & \\
\hline Chuí & & $2,00(n=1)$ & & \\
\hline El Passo 144 & $17,40(\mathrm{n}=10)$ & $0,25(\mathrm{n}=5)$ & $1,80(n=5)$ & $0,38(\mathrm{n}=2)$ \\
\hline Embrapa & & & & $3,50(\mathrm{n}=1)$ \\
\hline E-nova & & & & $0,00(\mathrm{n}=1)$ \\
\hline Epagri & & & & $1,00(\mathrm{n}=1)$ \\
\hline Pelota & $4,00(\mathrm{n}=1)$ & & & \\
\hline \multirow[t]{2}{*}{ Qualimax } & & $4,60(n=4)$ & $0,25(\mathrm{n}=1)$ & $19,25(\mathrm{n}=1)$ \\
\hline & Qualitá & & & $7,50(\mathrm{n}=1)$ \\
\hline Sabore & & & $0,00(\mathrm{n}=1)$ & $1,25(\mathrm{n}=1)$ \\
\hline Supremo & & $0,25(\mathrm{n}=1)$ & & \\
\hline Syngenta & $4,12(\mathrm{n}=2)$ & & & \\
\hline Taim & $20,00(\mathrm{n}=2)$ & & & $5,75(n=2)$ \\
\hline
\end{tabular}

Para análise estatística dos dados obtidos da parte aérea (PA) e sistema radicular (SR), foi utilizado o programa Genes (CRUZ, 2003) e as médias foram comparadas pelo teste tem nível de $5 \%$ de probabilidade de erro.

\section{RESULTADOS E DISCUSSÃO}

A partir do teste de sanidade verificou-se que a região de Camaquã foi a que apresentou maior incidência média de Alternaria padwickii $(10,61 \%)$, seguida pela região de Uruguaiana $(3,17 \%)$, região de Pelotas (2,46\%) e pela região de Rosário doSul(1,78\%).

A incidência $A$. padwickii pode variar muito dependendo do cultivar e do local. Neste trabalho verificou-se variação de $1,78 \%$ até $10,61 \%$, em média, por região, no entanto, GulART et al. (2005) verificaramqueaincidência de Alternaria sp. em sementes também coletadas no Rio GrandedoSul,variou de 38até 97\% noslotesamostrados e FRANCO et al. (2001) constataram que, dependendo da cultivar utilizada, a incidência pode variar de 3,01\% até
29,99\%. Estefato também foi verificado porCosta (1991) nos estados deGoiáse Tocantins, ondea cultivar Metica 1 foi a mais suscetível a A. padwickii.

De acordo com os dados observados na Tabela 1, verifica-se que a incidência de $A$. padwickiiapresentou uma variação bastante acentuada, entre as regiões e dentro dos mesmos cultivares, o que indica que a maior ou menor incidência, além de estar relacionada com a suscetibilidade do cultivar, está intimamente ligada ao manejo da cultura e também ao ambiente.

Na região de Camaquã, a cultivar que apresentou maior incidência de A. padwickii foi a BR IRGA-419, com 21,95\%. Na região de Uruguaiana foi a cultivar Qualimax, com 19,25\%, na região de Pelotas foi IRGA 417 com $5 \%$, já na região de Rosário do Sul foi a BR IRGA-410, com 6,58\% de incidência (Tabela 1).

No Rio Grande do Sul já foi observado por RIBEIRO (1989) que algumas cultivares como BR IRGA 409, 410, 412, 413 e 414 apresentam maior suscetibilidade à mancha de grãos, fato este que foi confirmado para BR IRGA 410 na região de Rosário do Sul. 


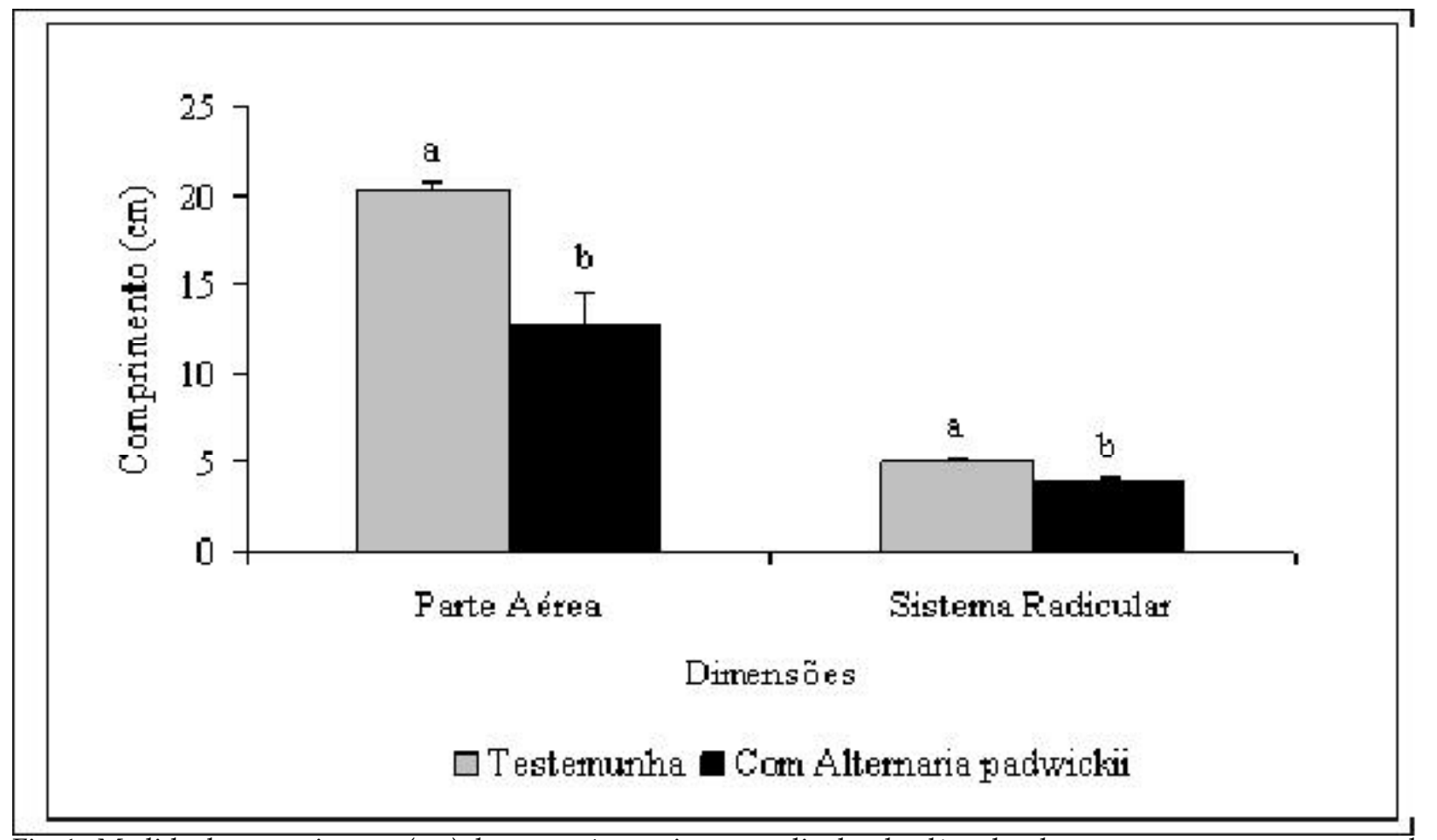

Fig. 1 - Medida do comprimento (cm) da parte aérea e sistema radicular de plântulas de arroz sem e com a presença de Alternaria padwickii. Médias seguidas pela mesma letra não diferem entre si pelo teste tem nível de $5 \%$ de probabilidade de erro. Pelotas, RS, 2006.

A emergência das plântulas oriundas desementes infectadas por A.padwickii foi reduzida em $88,0 \%$, nas condições ambientais testadas. Ou (1972) eIslam et al. (2000), em trabalhos anteriores, também constataram que a presença do fungo causa a morte de plântulas. A baixa emergência das plântulas infectadas por $A$. padwickii foi observada anteriormente causando descarte dos lotes, visto que há transmissão via sementes, inviabilizando os campos de produção de sementes (Costa, 1991; Ou, 1972). Já Islam et al. (2000) verificaram que a incidência de $A$. padwickii pode variar de 1,33 a 44,0\% dependendo da cultivar utilizada. Estes mesmos autores também verificaram que a utilização de fungicidas para o tratamento de sementes elimina a presença do fungo, independentemente da cultivar.

Verificou-se que as plantas que sobreviveram obtiveram redução de $36,6 \%$ no comprimento da parte aérea e de 25,5\% do sistema radicular (Fig 1).

Conformeobserva-senessetrabalhoa presença de $A$. padwickii, associado às sementes de arroz, poderá ocasionar vários problemas como baixa germinação das sementes, que poderá implicar na necessidade de replantio, o que onera o agricultor e também causa reduçãonodesenvolvimentodas plântulas. Asplântulas necrosadas (oriundas de sementes infectadas) apresentam dificuldade de desenvolver-se, pela diminuição da áreafoliarsadiadificultandoos processosdafotossíntese, ocasionando problemas de baixa produção, além de permanecerem na lavoura como fonte de inóculo. A dificuldade de desenvolver a parte aérea está também relacionada ao mau desenvolvimento das raízes.

O teste de inoculação em plântulas confirmaram a importância de A. padwickii na cultura do arroz, pois, em mais de $50 \%$ das plântulas, foi observada presença do patógeno.

Estes resultados vêm a confirmar o verificado por Costa (1991), que comprovou a transmissão de $A$. padwickii por sementes, evidenciando a redução da qualidade e corroborando com a hipótese de que a etiologia da mancha dos grãosé complexa e atribuída a vários patógenos, sendo que $A$. padwickii contribui de forma significativa.

Dessa forma, para diminuir as perdas na produção, ocasionadas pelos fungos, o melhor método é sempre o uso de sementes com boa qualidade fisiológica e sanitária, livres de contaminações ou dentro de padrões de tolerância estabelecidos para as principais culturas e doenças (REIS, 1986; REIS, 1987). Assim, testes rotineiros de sanidade de arroz não devem subestimar a importância de A. padwickii.

\section{AGRADECIMENTOS}

À Coordenação de Aperfeiçoamento Pessoal de Nível Superior, a pesquisadora do IRGA-Pelotas Maria da Graça e ao pesquisador da Embrapa Clima Temperado Daniel Franco. 
REFERÊNCIA

Amaral, H.M. Testes de sanidade de sementes de arroz. In: Soave, J.; Wetzel, M.V.S (Eds.). Patologia de sementes. Campinas: Fundação Cargill, 1987. p.357-370.

Amorin, L.; Salgado, G.L. Diagnose. In: Bergamin Filho, A.; Kimati, H.; Amorin, L (Eds). Manual de fitopatologia. 3.ed. São Paulo: Ed. Agronômica Ceres, 1995. p.224245.

BRASIL. Ministério da Agricultura. Regras para análise de sementes. Brasília: Ministério da Agricultura, 1992. $365 p$.

Conab. Companhia Nacional de Abastecimento. Levantamento safra 2005/2006. Disponível em:<http://www. conab.gov.br/download/safra.pdf>. Acesso em: 9 mai. 2006.

Costa, J.L.S. Alternaria padwickii e Curvularia lunata: patogenicidade e transmissão por sementes de arroz irrigado. Fitopatologia Brasileira, v.16, n.1, p.15-18, 1991.

CRuz, D.C. (Ed.).Programa Genes: aplicativo computacionalem genética e estatística. Viçosa: UFV, 2003. 648p.

Farias, C.R.J. DE; ReY, M.S.; CorrêA, C.L.; BeRTONCELlo, M.R.; PIERobom, C.R. Qualidade sanitária de sementes de diferentes cultivares de arroz. Fitopatologia Brasileira, v.29, p.147, 2004. Suplemento. Trabalho apresentado no CONGRESSO BRASILEIRO DE FITOPATOLOGIA, 37. 2004, Gramado. Anais. Gramado, 2004. Resumo 446.

Franco, D. F.; Ribeiro, A. S.; Nunes, C. D.; F erreira, E. Fungos associados a sementes de arroz irrigado no Rio Grande do Sul. Revista Brasileira de Agrociência, v.7, n.3, p.235-236, 2001.

Groth, D. Foliar disease. In: Webster, R., Gunnell, P. (Ed.). Compendium of rice disease. St. Paul: American. Phytopatological Society, 1992. p.14-21.

Groth, D.E.; Rush, M.C.; Hollier, C.A. Rice diseases and disorders in Lousiana. Baton rouge: Agricultural Experiment Station, 1991. 37p. (Bulletin, 828).

Gulart, C.; Bayer, T.M.; Cerbaro, L.; Lenz, G.; Zamolin, C.; CostA, I.F.D. Qualidade sanitária de sementes de arroz irrigado em diversas regiões produtoras do estado do Rio Grande do Sul. In: CONGRESSO BRASILEIRO DO ARROZ IRRIGADO 4.; REUNIÃO DA CULTURA DO ARROZ IRRIGADO 26., 2005, Santa Maria, RS. Resumos. Santa Maria: 2005. p.545.
Instituto Brasileirode Geografia e Estatística- IBGE.Levantamento sistemático da produção agrícola. Disponívelem:<http://www.ibge.gov.br/area>. Acessoem: 10 set. 2006.

IsLam, M.S.; Jahan, Q.S.A.; Bunnarith, K.; VIANGKum, S.; MerCA, S.D. Evaluation of seed health of some rice varieties under different conditions. Botanical Bulletin of Academia Sinica, v.41, p.293-297, 2000.

Malavolta, V.M.A.; Bedendo, I.P. Resistência de cultivares de arroz a manchas de grãos causadas pelos fungos Bipolaris oryzae, Microdochium oryzae e Phoma sorghina. Summa Phytopathologica, v.25, n.4, p.313-318, 1999.

Ou, S.H. (Ed.). Rice diseases. Surrey: Commonwealth Mycological Institute, 1972. 368p.

ReIs, E.M. Patologia de sementes de cereais de inverno. Um enfoque epidemiológico. In: SIMPÓSIO BRASILEIRO DE PATOLOGIA DE SEMENTES 4., Gramado, RS. Anais. Campinas: Fundação Cargill, 1986. p.101-104.

ReIs, E.M. Patologia de sementes de cereais de inverno. São Paulo: CNDA, 1987.32p.

RIBEIRO, A.S. Doenças do arroz irrigado. Pelotas: EMBRAPA/ UEPAE, 1979. 44p. (Circular Técnica, 3).

Ribeiro, A.S.; Mariot, C. Condições fitossanitárias das sementes de arroz no Rio Grande do Sul. Lavoura Arrozeira, v.40, n.371, p.20-25, 1987.

Ribeiro, A.S. Controle integrado das doenças do arroz irrigado. Pelotas: EMBRAPA-CPATB, 1989.29p. (Circular Técnica, 3).

Soave, J.; Pizzinatto, M.A.; Usberti Junior, J.A.; Camargo, O.B.A.; VILLELA, O.V.Selection of ricecultivars resistant to some pathogens using seed health testing. Pesquisa Agropecuária Brasileira, v.19, n.4, p.449-453, 1984.

Soave, J.; Prabhu, A.S.; Ricci, M.T.T.; Barros, L.; Souza, N.R.G.; Curvo, R.C.V.; FerReIRA, R.P.; SOBRAL, C.A.M. Etiologia de manchas de sementes de cultivares de arroz de sequeiro no Centro-Oeste brasileiro. Summa Phytopathologica, v.23, n.2, p.122-127, 1997.

Webster, R.K.; Gunnell, P.S. Compendium of rice diseases. St. Paul: The American Phytopathological Society. 1992. 62p.

Recebido em 10/10/06

Aceito em 21/8/07 